\title{
Expression and prognostic significance of $C B X 2$ in colorectal cancer: database mining for CBX family members in malignancies and vitro analyses
}

He Zhou ${ }^{1,3+}$, Yongfu Xiong ${ }^{2,3+}$, Zuoliang Liu ${ }^{1,3}$, Songlin Hou ${ }^{1,3}$ and Tong Zhou ${ }^{1,3^{*}}$ (D)

\begin{abstract}
Background: The Chromobox (CBX) domain protein family, a core component of polycomb repressive complexes 1 , is involved in transcriptional repression, cell differentiation, and program development by binding to methylated histone tails. Each CBX family member plays a distinct role in various biological processes through their own specific chromatin domains, due to differences in conserved sequences of the CBX proteins. It has been demonstrated that colorectal cancer (CRC) is a multiple-step biological evolutionary process, whereas the roles of the CBX family in CRC remain largely unclear.
\end{abstract}

Methods: In the present study, the expression and prognostic significance of the CBX family in CRC were systematically analyzed through a series of online databases, including Cancer Cell Line Encyclopedia (CCLE), Oncomine, Human Protein Atlas (HPA), and Gene Expression Profiling Interactive Analysis (GEPIA). For in vitro verification, we performed cell cloning, flow cytometry and transwell experiments to verify the proliferation and invasion ability of CRC cells after knocking down CBX2.

Results: Most CBX proteins were found to be highly expressed in CRC, but only the elevated expression of CBX2 could be associated with poor prognosis in patients with CRC. Further examination of the role of CBX2 in CRC was performed through several in vitro experiments. CBX2 was overexpressed in CRC cell lines via the CCLE database and the results were verified by RT-qPCR. Moreover, the knockdown of CBX2 significantly suppressed CRC cell proliferation and invasion. Furthermore, the downregulation of CBX2 was found to promote CRC cell apoptosis.

Conclusions: Based on these findings, CBX2 may function as an oncogene and potential prognostic biomarker. Thus, the association between the abnormal expression of CBX2 and the initiation of CRC deserves further exploration.

Keywords: Chromobox, Colorectal cancer, CBX2, Prognosis, Cell proliferation

*Correspondence: zhoutong@nsmc.edu.cn

${ }^{\dagger} \mathrm{He}$ Zhou and Yongfu Xiong contributed equally to this work

${ }^{1}$ The Second Department of Gastrointestinal Surgery, Affiliated Hospital of North Sichuan Medical College, 63 Wenhua Road, Nanchong 637000,

Sichuan Province, China

Full list of author information is available at the end of the article

†Yongfu Xiong is the co-first author of this article.

\section{Background}

Colorectal cancer (CRC) remains one of the top three causes of tumor-related deaths worldwide [1]. In 2019, an estimated 145,600 new cases of CRC and 51,020 deaths from the disease were reported in the USA [2]. Although the incidence of CRC has decreased in developed countries, due to improved treatments and early screening, the 5-year overall survival (OS) rate of CRC

(c) The Author(s) 2021, Corrected publication 2021. Open Access Open Access This article is licensed under a Creative Commons Attribution 4.0 International License, which permits use, sharing, adaptation, distribution and reproduction in any medium or format, as long as you give appropriate credit to the original author(s) and the source, provide a link to the Creative Commons licence, and indicate if changes were made. The images or other third party material in this article are included in the article's Creative Commons licence, unless indicated otherwise in a credit line to the material. If material is not included in the article's Creative Commons licence and your intended use is not permitted by statutory regulation or exceeds the permitted use, you will need to obtain permission directly from the copyright holder. To view a copy of this licence, visit http://creativecommons.org/licenses/by/4.0/. The Creative Commons Public Domain Dedication waiver (http://creativecommons.org/publicdomain/zero/1.0/) applies to the data made available in this article, unless otherwise stated in a credit line to the data. 
patients in developing countries is still not ideal [3, 4]. The tumor node metastasis (TNM) staging system developed by the American Joint Committee on Cancer and Union for International Cancer Control is the most universal tumor staging standard in the world and an important reference index for predicting the prognosis of tumor patients [5]. Increasing evidence has indicated that CRC is a highly heterogeneous disease with multiple molecular pathways involved in its progression [6]. Nevertheless, current TNM staging systems cannot reflect the intrinsic biological heterogeneity of CRC, especially in patients with atypical early symptoms. This results in $<50 \%$ of CRC being diagnosed early, with certain CRC patients diagnosed through this system already presenting with distant metastasis [7]. Therefore, to improve the diagnosis, prognosis and targeted therapy of CRC, it is necessary to find biomarkers that can accurately predict its progression and therapeutic effect, and explore the mechanism of CRC development at the molecular level.

Chromatin has been divided into different domains according to the function of associated genomes, including euchromatin and heterochromatin [8]. The structural distribution and assembly of chromatin are influenced by numerous factors. The proteins that control chromatin dynamics play a pivotal role in the epigenetic regulation of gene expression [9]. The Chromobox (CBX) family proteins are crucial components of chromatin-related complexes heterochromatin protein 1 (HP1) and polycomb (Pc), which are involved in transcriptional regulation, chromatin structural modification, and the cell development process [10]. To date, eight members of the CBX family proteins have been identified in eukaryotic organisms, each containing a single $\mathrm{N}$-terminal chromosomal domain[11]. The CBX family can be subdivided into two groups: One consisting of CBX1, CBX3, and CBX5, with a similar structural feature of HP1 homologs (HP1 $\alpha$, HP1 $\beta$, and HP1 $\gamma$ ), and another made of Pc paralog proteins, known as CBX2, CBX4, CBX6, CBX7, and $\mathrm{CBX} 8$, which can recruit Pc repressive complexes 1 to maintain expression patterns of different genes during cell proliferation [12].

CBX family proteins are widely involved in a variety of biological process in all metazoans, including cell cycle control, induction of cell differentiation, and maintenance of pluripotency of embryonic stem cells [13]. Existing evidence has revealed that the dysregulation of CBX proteins results in numerous cell divisions that initiate cancer [14]. For instance, three isoforms of HP1 (CBX1, CBX3, and CBX5) act as organizers of pericentric heterochromatin in conjunction with $\mathrm{H} 3 \mathrm{~K} 27 \mathrm{me} 3$, which hinders cell cycle progression, leading to transcriptional activation, cell proliferation and cancer [15]. Recent studies have suggested that $\mathrm{CBX} 2$ and $\mathrm{CBX} 6$ act as oncogenes in hepatocellular carcinoma (HCC). The overexpression of both CBX2 and CBX6 is associated with poor prognosis in HCC patients [16, 17]. Xia et al. [18] demonstrated that mutation of the CBX4 gene causes the transcriptional repression of proto-oncogenes, and can interact with $\mathrm{CBX} 2$ and $\mathrm{Bmi}-1$ to alter pre-splicing mRNA. This ultimately causes an abnormal transformation of cells. Unlike other Pc family members, the role of CBX7 as a proto-oncogene or suppressor depends on its specificity in cells and tissues, as well as various epigenetic factors [19].

CBX2 is a key regulator of developmental genes. It shows a stronger effect on cancer progression than other CBX members by repressing the transcription of the Ink4a/Arf locus [20]. Further research has shown that CBX2 is the main protein expressed in ESC and can repress the expression of pluripotency genes that promote stem cell differentiation [20,21]. Although CBX2 has been reported to be abnormally expressed in a number of cancer types, the role of CBX2 in CRC remains largely unclear. In the present study, integrated analysis of the CBX protein family was performed through several online databases, with the purpose of searching for potential therapeutic biomarkers of CRC patient survival.

\section{Methods}

\section{Cancer cell line encyclopedia (CCLE) database analysis}

CCLE (https://portals.broadinstitute.org/ccle/home) is an open-access database covering large-scale deep sequencing information of 947 human cancer cell lines from $>30$ varieties of tissue sources. The mRNA expression of the CBX family in cell lines derived from different tumor types was analyzed by CCLE, to deepen the understanding of DNA mutations, gene expression and chromosome copy number information for specific genes. Gene expression data of the CBX family was downloaded directly from the CCLE website. According to the website, raw microarray data of CRC cell lines were converted to a single value for each probeset using the Robust Multi-array Average algorithm and quantile normalization.

\section{Oncomine database analysis}

Oncomine (http://www.oncomine.org) is a classic oncogene chip database, which integrates data from The Cancer Genome Atlas (TCGA) and Gene Expression Omnibus databases. It provides a variety of analytical tools and visually shows the differences between cancer and normal tissue expression, co-expression analysis, mutation analysis, etc. In the current study, the mRNA expression of distinct $\mathrm{CBX}$ family proteins was analyzed 
between tumor and normal tissues in different types of cancers. The results were filtered using the following threshold: Fold change, $2 ; \mathrm{P}=1 \times 10^{-4}$; gene rank, top $10 \%$.

\section{The human protein atlas database (HPA) analysis}

The HPA database (https://www.proteinatlas.org/) provides information on the tissue and cell distribution of all 26,000 human proteins and is publicly available free of charge [22]. This database uses special antibodies and immunohistochemical (IHC) techniques to examine the distribution and expression of each protein in 48 normal human tissues, 20 tumor tissues, 47 cell lines and 12 blood cells. These samples were collected from different clinical individuals, ensuring that the staining results were sufficiently representative. In the present study, IHC images of the CBX protein expression in clinical samples of patients with CRC and normal tissues were obtained from the HPA database.

\section{Gene expression profiling interactive analysis (GEPIA) database analysis}

GEPIA (http://www.gepia.cancer-pku.cn/http://www. gepia.cancer-pku.cn/) is an open-access database for the interactive exploration of multiple cancer genomics datasets. The utilization of GEPIA significantly reduces the barriers in accessing complex genomic data and facilitates rapid, intuitive, high-quality access to molecular profiling and clinical prognostic correlations for largescale cancer genomics projects. The website query interface is combined with multiple databases that store DNA copy numbers and mRNA expression, gene coexpression, Reverse Phase Protein Array, DNA methylation and clinical survival data. This allows researchers to investigate the interaction between gene alterations and clinical case samples by directly entering gene names. Kaplan-Meier plots were used to compare OS and disease-free survival (DFS) in CRC cases with the mRNA expression of each CBX member.

\section{Cell culture}

The CRC HCT116 and HT29 cell lines, and the normal human colon mucosal epithelial cell line NCM460, were obtained from the Cell bank of the Chinese Academy of Science where they were characterized by mycoplasma detection, DNA -Fingerprinting (Short Tandem Repeat, STR), isozyme detection and cell vitality detection. Cells were cultured in McCoy's 5 A medium (Gibco, Carlsbad, CA) containing 10\% fetal bovine serum (PAN-Biotech, Adenbach, Bavaria) in an incubator with $5 \% \mathrm{CO}_{2}$ at $37^{\circ} \mathrm{C}$.

\section{Lentivirus transduction and stable cell line selection}

The lentivirus-mediated GV248 vector (Genechem, China) was used to express short hairpin RNA (shRNA) targeting $\mathrm{CBX} 2$. The shRNAs sequences targeting CBX2 were as follows:5' - CCGG GAG GTC AAC CCA GGA GAG AGA CTCGAG TCT CTC TCC TGG GTT GAC CTC TTTTTG-3'. The 293 T cells were transfected with Lv-shRNA vector for $48 \mathrm{~h}$, the liquid supernatant was collected. Then, HCT116 and HT29 cells $\left(1 \times 10^{5}\right.$ cells/ well) were seeded into 24-well plate and cultured in medium for $24 \mathrm{~h}$, then the liquid supernatant was transfected into HCT116 and HT29 cells at a multiplicity of infection (MOI) of 10. The nontarget green fluorescent protein (GFP)-LV vectorwas used as negative control (sh-Ctrl). The stable cell lines were selected using puromycin $(4 \mu \mathrm{g} / \mathrm{ml}) 72 \mathrm{~h}$ after transfection. The medium containing puromycin was replaced every three days for two weeks.

\section{RNA isolation and RT-qPCR}

Total RNA was extracted from cells using RNAiso Plus reagent (Takara, Dalian, China). The Prime Script RT Reagent Kit (Takara) was used to perform reverse transcription following the manufacturer's protocol. RTqPCR was performed on a Bio-Rad CFX96 system (Bio-Rad, Hercules, CA). Glyceraldehyde-3-phosphate dehydrogenase (GAPDH) was used as a normalizing control. The primer sequences used in the present study were as follows: CBX2, 5'-GGA ACA TGA GAA GGA GGT GCA G-3' (forward) and 5'-GAA GAG GAG GAA CTG CTG GAC T-3' (reverse); GAPDH, 5'-CAG GAG GCA TTG CTG ATG AT-3' (forward) and 5'-GAA GGC TGG GGC TCA TTT-3' (reverse).

\section{Western blotting}

Cells were harvested at a density of $>90 \%$ and subsequently lysed in RIPA buffer (Beijing Solarbio Science \& Technology, China) on ice. Equal amounts of protein lysate $(15 \mu \mathrm{g})$ were separated using $10 \%$ sodium dodecyl sulfate polyacrylamide gels and then transferred onto polyvinylidene fluoride membranes (Millipore, County Cork, Ireland) via electroblotting. Following blocking in rapid block buffer (Sangon Biotech, China) for $15 \mathrm{~min}$, the membranes were incubated at $4{ }^{\circ} \mathrm{C}$ overnight with relevant primary antibodies. The Horse Radish Peroxidase-conjugated secondary antibodies (dilution, 1:5000, Cat. No. SE134; Solarbio) were then used to incubate the membranes for $1 \mathrm{~h}$ at room temperature. The protein bands were detected by enhanced chemiluminescence (Vilber, Collegien, France). The primary antibodies used were rabbit anti-CBX2 (dilution, 1:2000, Cat. No. 
ab80044; Abcam), and rabbit anti-GAPDH (dilution, 1:1000, Cat. No. 2118; Cell Signaling Technology).

\section{Cell colony formation and invasion assays}

Colony formation assay was used to test the cell proliferation capacity following CBX2 knockdown. Transfected cells were seeded in six-well plates in triplicate at a density of 500 cells/well and incubated at $37^{\circ} \mathrm{C}$ for 2 weeks. The cell colonies were then washed with PBS, fixed with $4 \%$ paraformaldehyde for $20 \mathrm{~min}$ and stained with $0.2 \%$ crystal violet for $30 \mathrm{~min}$. Cell colonies with $>50$ cells were identified as positive colonies and the colony numbers were counted under a microscope.

Transwell assay was used to evaluate the invasion ability of colon cancer cells after knocking down CBX2. In brief, $1 \times 10^{5}$ cells were plated in the upper chamber coated of 24-well plate with Matrigel and supplemented with serum-free medium. The lower chamber was filled with culture medium containing 15\% FBS. Incubation was carried out for $48 \mathrm{~h}$ at $37^{\circ} \mathrm{C}$. The noninvasive cells were scraped off with cotton swabs. The cells that had successfully translocated were fixed with $4 \%$ paraformaldehyde, stained with $0.5 \%$ crystal violet. The number of invaded cells was observed by using an inverted microscope and calculated by counting six random views.

\section{Cell apoptosis assay}

Flow cytometer (Cytoflex, Beckman Coulter, California, USA) is used to detect cells apoptosis after transfection. Transfected cells were disaggregated using $0.25 \%$ trypsin-EDTA solution and washed in PBS twice. Next, $1 \times 10^{6}$ cells were resuspended in PBS and stained with APC-conjugated Annexin V (Cat. No. 88-8007-72, eBioscience, San Diego, California, USA) and 4',6-diamidino-2-phenylindole (Cat. No. D3571, Invitrogen, Carlsbad, California, USA), according to the manufacturer's recommendations.

\section{Statistical analysis}

The GraphPad Prism (Version 8.0 GraphPad Software, CA) was used for statistical analysis. The significance of differences between groups was evaluated using the Student's $t$-test. Statistical significance of CBX family expression between CRC and normal tissues from the Oncomine database was provided by the program. Survival data of CBX family mRNA expression were obtained from the GEPIA database. Survival curves were plotted using the Kaplan-Meier method and compared using the log-rank test. $\mathrm{P}<0.05$ were considered to indicate a statistically significant difference.

\section{Results}

\section{Dysregulated mRNA expression of CBX family members in CRC}

The expression of CBX2 in CRC ranked 21th highest among all cancer types, as determined by CCLE analysis (Fig. 1a). Oncomine database analysis showed that the mRNA levels of CBX2, CBX3, CBX4, CBX5, and CBX8 were significantly higher in CRC than in normal tissues, based on a wide variety of datasets. Conversely, CBX6 and CBX7 were confirmed to have a lower expression in CRC, as compared with normal tissue (Fig. 1b).

\section{Association between CBX mRNA expression and pathological stages of CRC}

Next, a large sample from the TCGA dataset was analyzed in the GEPIA database. Consistent with the Oncomine database, CBX1-5 and CBX8 transcripts in colon and rectal adenocarcinoma tissues were higher than in normal tissues (Fig. 2a-h). The association between CBX expression and CRC pathological stage was then investigated. Of note, significantly statistical differences between tumor stages I-IV were only identified in the $\mathrm{CBX} 2$ group $(\mathrm{P}=0.021$; Fig. $3 \mathrm{~b})$. There was no association between the other $\mathrm{CBX}$ members and pathological stage $(P>0.05$; Fig. 3a and $\mathrm{c}-\mathrm{h})$.

\footnotetext{
(See figure on next page.)

Fig. 1 mRNA expression of CBX family members in different types of cancer. a mRNA expression level of CBX2 from the CCLE database. The CBX2 mRNA expression level ranked 21 th among different human types of cancer (shown in red frame). $\mathbf{b}$ mRNA expression levels of CBX family members in various types of cancer vs. normal tissues in the Oncomine database. The blue box in the graph indicates that the target gene was lowly expressed in the corresponding tumor, while red indicates highly expressed genes, with statistically significant differences $\left(P=1 \times 10^{-4}\right)$. The number in the cell represents the number of studies that meet the set threshold. The color of the cells is determined by the rank of gene expression differences. CBX Chromobox, CCLE Cancer Cell Line Encyclopedia
} 
a

CBX2 - Entrez ID: 84733

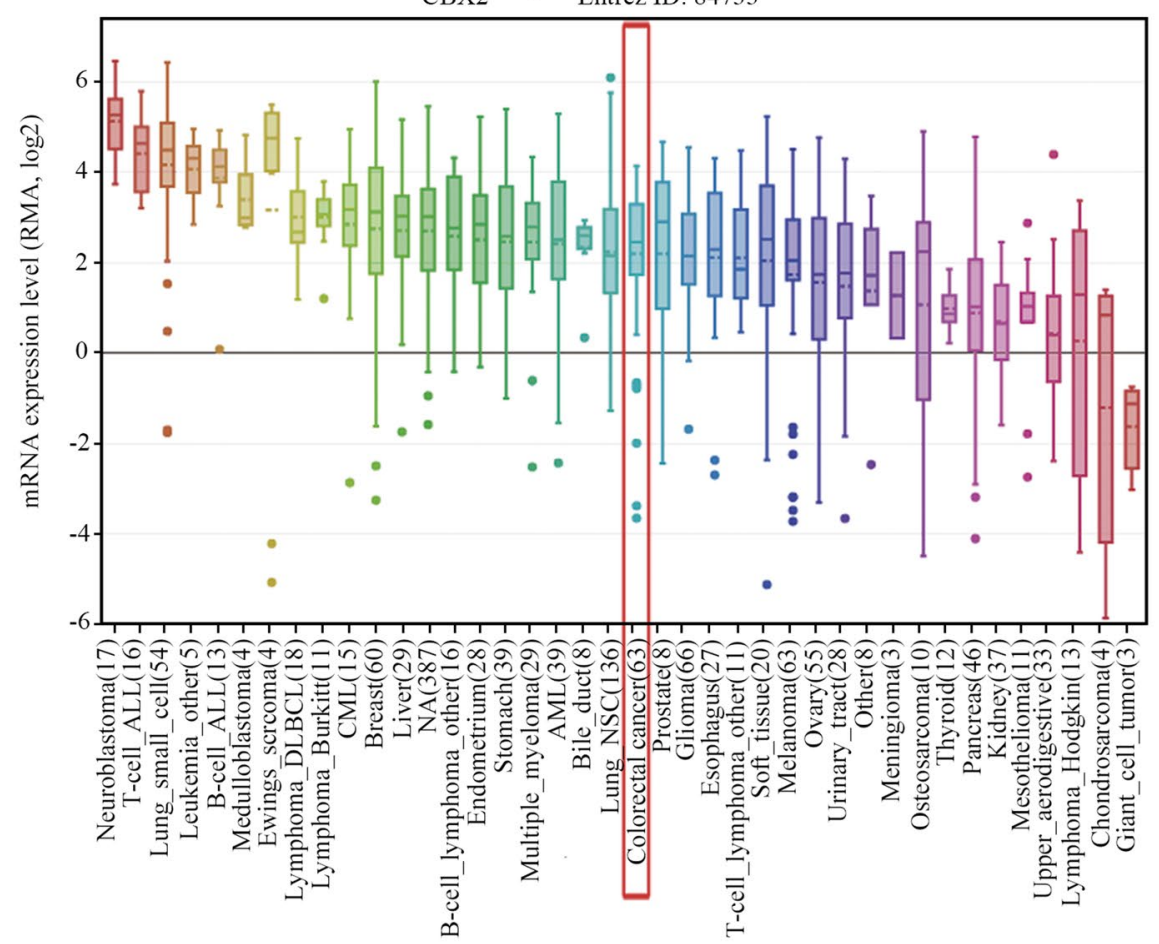

b

\begin{tabular}{|c|c|c|c|c|c|c|c|c|c|c|c|c|c|}
\hline Analysis type by cancer & 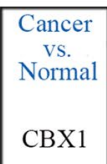 & 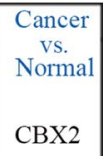 & $\begin{array}{c}\text { Cancer } \\
\text { vs. } \\
\text { Normal } \\
\text { CBX3 }\end{array}$ & \multicolumn{2}{|c|}{$\begin{array}{l}\text { Cancer } \\
\text { Vs. } \\
\text { Normal } \\
\text { CBX4 }\end{array}$} & \multicolumn{2}{|c|}{$\begin{array}{c}\begin{array}{c}\text { Cancer } \\
\text { vs. } \\
\text { Normal } \\
\text { CBX5 }\end{array} \\
\text {. }\end{array}$} & \multicolumn{2}{|c|}{$\begin{array}{l}\text { Cancer } \\
\text { vs. } \\
\text { Normal } \\
\text { CBX6 }\end{array}$} & \multicolumn{2}{|c|}{$\begin{array}{l}\begin{array}{c}\text { Cancer } \\
\text { vs. } \\
\text { Normal } \\
\text { CBX7 }\end{array} \\
\text {. }\end{array}$} & \multicolumn{2}{|c|}{ 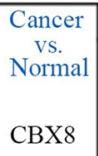 } \\
\hline Bladder cancer & & 1 & $\overline{1}$ & & & & & & 1 & & 2 & & \\
\hline Brain and CNS cancer & & 2 & 5 & & & & 1 & & 5 & 1 & 6 & & \\
\hline Breast cancer & & 5 & 1 & 4 & & & & & & 1 & 12 & 1 & \\
\hline Cervical cancer & 1 & & 2 & & & 2 & & & 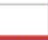 & & 1 & & \\
\hline Colorectal cancer & & 8 & 8 & 12 & & 8 & & & 1 & & 6 & 5 & \\
\hline Esophageal cancer & 1 & & 2 & & & & & 1 & & & & & \\
\hline Gastric cancer & 2 & 2 & 1 & 2 & & & & & & & & & \\
\hline Head and neck cancer & 1 & & 10 & & & & & & & & & & \\
\hline Kidney cancer & & & 4 & & & & & & & & & 1 & \\
\hline Leukemia & 1 & & & 1 & & 2 & 3 & & 1 & 1 & 3 & & \\
\hline Liver cancer & 2 & & & & & & & & & & 1 & & \\
\hline Lung cancer & 3 & 3 & 3 & & & 1 & & & & & 5 & & \\
\hline Lymphoma & 1 & & 3 & & 4 & 3 & & & & & & & \\
\hline Melanoma & & & 2 & & & & & & & & 1 & & \\
\hline Myeloma & & & & & & & & & & & & & \\
\hline Other cancer & 1 & 2 & 3 & 2 & & 3 & 1 & & & & 2 & 1 & \\
\hline Ovarian cancer & 1 & & 1 & & & & & & & & 3 & & \\
\hline Pancreatic cancer & & & & & & & & & & & & & \\
\hline Prostate cancer & & & 1 & 2 & & & & & & & & & \\
\hline Scrcoma & 8 & & 6 & 1 & & & & 1 & & & 2 & & \\
\hline Significant unique analyses & \begin{tabular}{|l|l|}
21 & 3 \\
\end{tabular} & \begin{tabular}{l|l}
23 & 3 \\
\end{tabular} & 52 & 24 & 4 & & 5 & 2 & 8 & 3 & 43 & 8 & \\
\hline Total unique analyses & 348 & 273 & 361 & 32 & & & & 29 & 98 & & 57 & & 43 \\
\hline
\end{tabular}

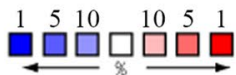

Fig. 1 (See legend on previous page.) 


\section{Protein expression of CBXs in patients with CRC}

To further verify the trend of CBX expression in CRC tissues, the results of IHC analysis of CBXs were obtained from the HPA database (Fig. 4). According to the degree of staining, the protein expression of CBX1-5 and CBX8 in CRC tissues was also higher than that in normal tissues. Conversely, CBX6 and CBX7 were lower in CRC tissues, as compared to normal tissues. These results were consistent with the mRNA expression.

\section{Association between CBX family expression and prognosis in patients with CRC}

Further assessment by GEPIA database analysis of the prognostic effect of the CBX family mRNA expression in CRC revealed that a high CBX2 expression in patients was significantly associated with a worse disease free survival (DFS), as compared with a low CBX2 expression $(\mathrm{P}=0.049$; Fig. $6 \mathrm{~b})$. However, no significant difference $(\mathrm{P}>0.05)$ was observed in the OS and DFS associated with or without mRNA expression alteration in the remaining CBX family members (Figs. 5 and $6 \mathrm{a}$ and $\mathrm{c}-\mathrm{h}$ ). A comparison of the above databases indicated that $\mathrm{CBX} 2$ might be a potential prognostic target for CRC.

\section{CBX2 knockdown inhibited CRC cells proliferation and invasion}

Through the CCLE database, we found that the expression of CBX2 in HCT116 and HT29 cell lines was significantly higher, compared with other CRC cell lines (Fig. 7a). Subsequently, the results in the CCLE database were verified by RT-qPCR experiment (Fig. 7b). Accumulating evidence has demonstrated that cancer is closely associated with abnormal proliferation [23]. A large number of cases in the GEPIA database have suggested that an elevated CBX2 expression can lead to poor prognosis. We therefore wondered whether CBX2 was involved in maintaining the malignant phenotype of CRC cells. To explore the biological function of CBX2 in the tumorigenesis of $\mathrm{CRC}$, we investigated whether
CBX2-knockdown could inhibit cell proliferation. First, as shown in Fig. 7c, the protein expression of CBX2 was significantly inhibited in HCT116 and HT29 cell lines following transfection by western blotting. Next, a colony formation assay indicated that CBX2-knockdown led to a marked reduction of colony numbers in HCT116 and HT29 cell lines (Fig. 8a). Furthermore, flow cytometry, performed to determine whether apoptosis was involved in the CBX2-knockdown-induced inhibition of proliferation, showed apoptotic cells were significantly increased in the CBX2-knockdown group, as compared with the sh-Ctrl group (Fig. 8b). In addition, as compared with the sh-Ctrl group, transwell assays revealed a significant reduction in cell invasion in the CBX2-knockdown group (Fig. 8c).

\section{Discussion}

It has been well-established that the process of CRC initiation can be attributed to cumulative genomic mutations $[24,25]$. Mutations of numerous oncogenes and tumor suppressor genes during the multiple-step evolution of CRC could lead to the transformation of tissues from normal epithelial to carcinoma [26]. In addition to gene mutations that lead to the activation of proto-oncogenes or inactivation of tumor suppressor genes, abnormal alterations in epigenome modification also play a key role in the initiation and progression of a variety of cancers, including lung, breast and liver cancer, and CRC [27-30].

Epigenetics, defined as a stable genetic phenotype resulting from changes in chromosomes without changes in DNA sequence. Several studies have indicated that endogenous and exogenous stimulation can reorganize the chromatin structure of cells, resulting in the expression or suppression of abnormal genes, allowing them to obtain the hallmarks of cancer [31, 32]. In addition to the appearance of tumor markers, epigenetic alterations are another pivotal events during the cancer process, including abnormal DNA methylation and histone modifications [33]. Cumulative evidence has shown that chromosomal instability and microsatellite instability are the two main ways

(See figure on next page.)

Fig. 2 Expression analysis of CBX family members in CRC and normal tissues (GEPIA database). Box plots derived from gene expression data comparing expression levels of a specific CBX family member in $C R C$ and the corresponding normal tissue. Comparison of a CBX1, $\mathbf{b} C B X 2$, $\mathbf{c} C B X 3$, $\mathbf{d} C B X 4, \mathbf{e} C B X 5, \mathbf{f} C B X 6, \mathbf{g} C B X 7$, and $\mathbf{h} C B X 8$ mRNA expression. *P $<0.05$. COAD colon adenocarcinoma, $R E A D$ rectum adenocarcinoma, $T$ tumor, N normal, CBX Chromobox, CRC colorectal cancer, GEPIA Gene Expression Profiling Interactive Analysis 

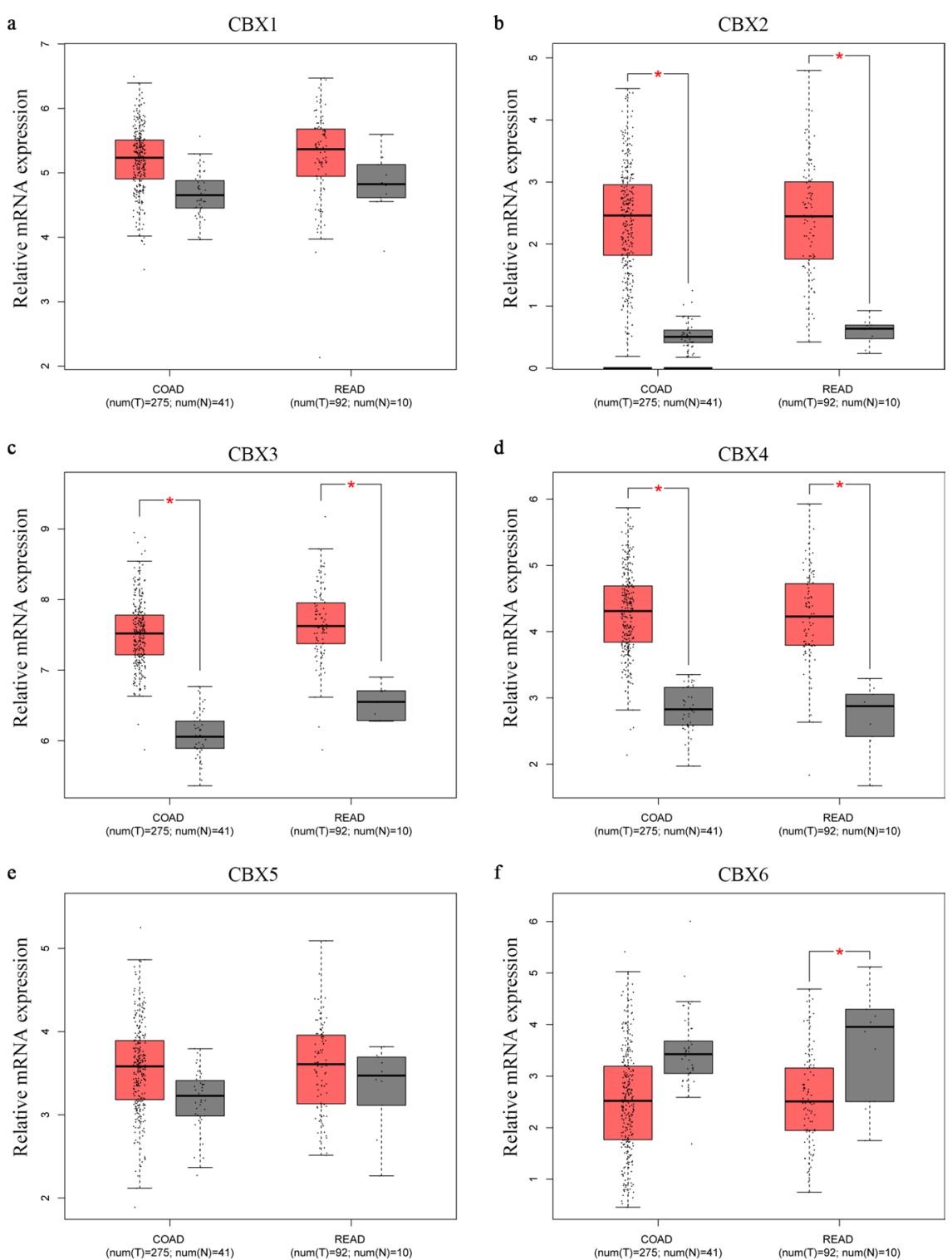

f
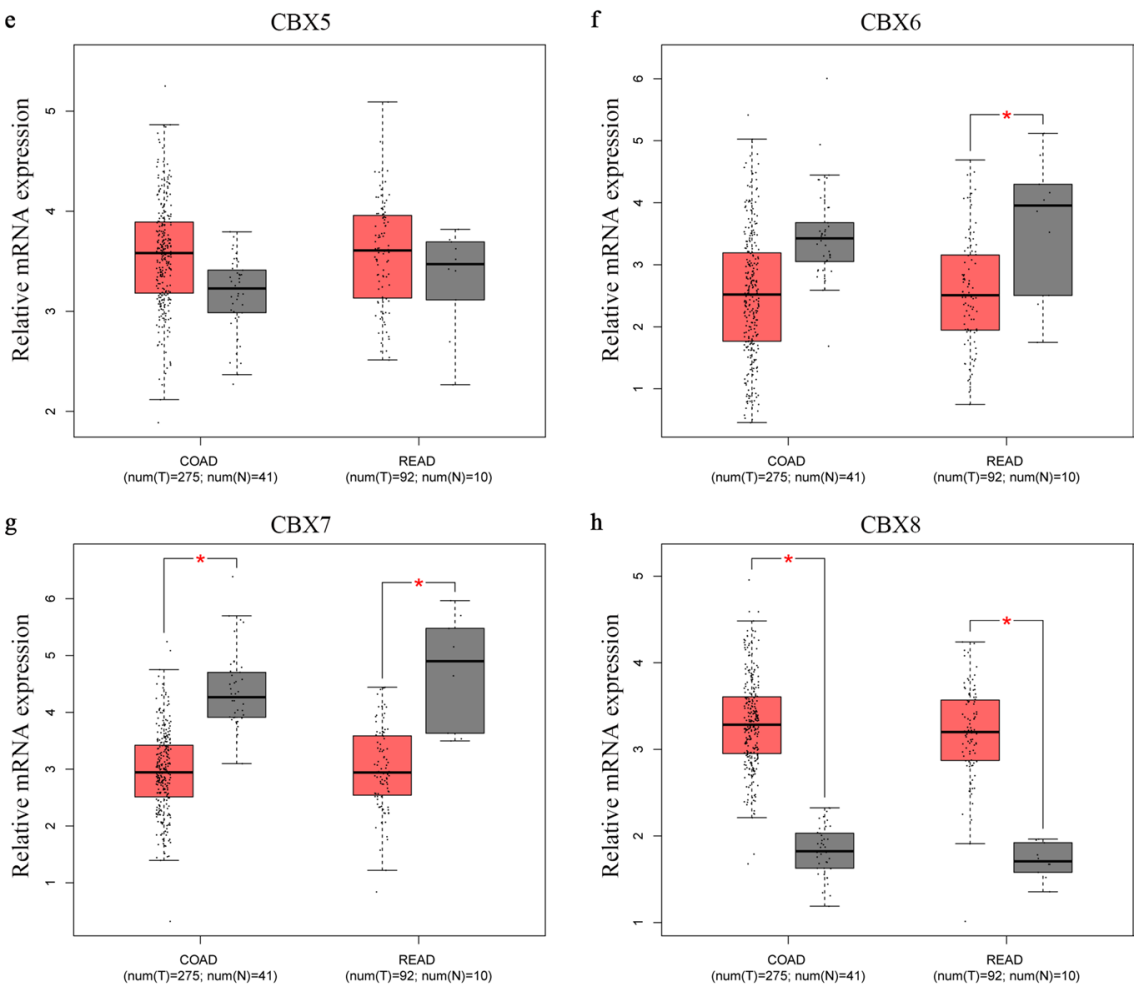

Fig. 2 (See legend on previous page.)

Tumor tissue

Normal tissue 
that cause CRC genome instability. However, emerging evidence has identified a third type of CRC characterized by DNA hypermethylation, which is defined as having a $\mathrm{CpG}$ island methylation phenotype (CIMP) [34]. At present, pathological examination based on the pathological staging and histological characteristics of tumors is still the most accurate method to assess the prognosis of patients with CRC. Several studies suggested that CIMP-positive tumors can lead to a poor overall survival prognosis, and show a close correlation with clinicopathological and molecular characteristics, including tumor location, gender, and whether there are KRAS and BRAF mutations [35]. Moreover, a cohort study of 206 patients with stage III CRC suggested that CIMP-positive is associated with unfavorable prognosis [36]. Futhermore, some researches indicated that poor prognosis of CIMP-positive CRC is due to BRAF mutations [37]. Therefore, the reversibility of epigenetic therapies for these changes has profound implications for the prevention and clinical prognosis of cancer patients [38].

CBX2, also known as CDCA6 or M33, is a crucial component of PcG histone complexes involved in epigenetic controls [39]. The PcG complexes are highly conserved in evolution and contain a variety of enzymes that catalyze histone modification to act as gene suppressors or activators [40]. Increasing evidence has suggested that phenotypic changes caused by histone posttranslational modification dysregulation are one of the pathogenic mechanisms of human carcinogenesis. These events are often described as the biological transformation of cellular molecular hallmarks into a malignant molecular phenotype process [41]. Epigenetic control has been considered a prior response to gene activity caused by changes in chromatin structure, which stems from self-maintenance, post-translational modification of mRNA, and binding between different histones [42]. Hence, further research on the epigenome will greatly improve our understanding of the mechanisms of complex diseases, including cancer. For instance, Chen et al. found that CBX2 was abnormally highly expressed in breast cancer, and an elevation that led to poor prognosis [43]. Clermont et al. reported that CBX2 suppressed cell viability by activatingcaspase-3 enzyme, which caused apoptosis in metastatic prostate cancer cells [44]. Further studies found the knockdown of CBX2 to facilitate the sumoylation activation of SUMO2/3, leading to the occurrence of leukemia [45]. Mechanistically, it was revealed by Mao et al. [16] that CBX2 could activate the Hippo pathway via the downregulation of the Yes-associated protein (YAP) expression, thus regulating the proliferation, apoptosis and DNA repair of hepatocellular carcinoma cells. Moreover, CBX2 was also reported by Han et al. [46] to act as a tumor promoter by binding miRNA let-7a to downregulate the expression of rat sarcoma virus (RAS), resulting in the progression of osteosarcoma. In addition, previous studies have confirmed the correlation between abnormal expression of some members of the CBX family and tumor prognosis. For example, elevated expression of CBX1/2/3/6/8 are associated with poor overall survival (OS) in hepatocellular carcinoma (HCC) patients [47]. Liang et al. found that high expression of CBX1/2/3 are correlatated with unfavorable relapsefree survival (RFS) in breast cancer (BC) patients [48]. Jiang et al. confirmed that CBX4 overexpression is associated with poor prognosis in cell renal cell carcinoma (ccRCC) patients [49].

In the present study, a total of eight CBX family members were evaluated in 20 common human samples and normal control tissues through the Oncomine database. The Oncomine database results showed that most members of CBX were highly expressed in $\mathrm{CRC}$, implying their unique roles in the disease. The present analysis further confirmed this conclusion based on a large-sample TCGA cohort study. Intriguingly, in the survival analysis of CBX family members in patients with $C R C$, it was found that only a high CBX2 mRNA expression was associated with poor outcome, as compared with patients with a low mRNA

(See figure on next page.)

Fig. 3 Association between mRNA expression of CBXs and tumor stages in patients with CRC (GEPIA database). a CBX1, b CBX2, c CBX3, d CBX4, $\mathbf{e} C B X 5, \mathbf{f} C B X 6, \mathbf{g} C B X 7$, and $\mathbf{h} C B X 8$. In the violin plots, the white dots indicate the median; the black box indicates the quartile range; the thin black line indicates 95\% confidence interval; the size of the red area indicates the density. F-value, statistical value of the $F$ test; $\operatorname{Pr}(>\mathrm{F}), \operatorname{P-value.} C B X$ Chromobox, CRC colorectal cancer, GEPIA Gene Expression Profiling Interactive Analysis 


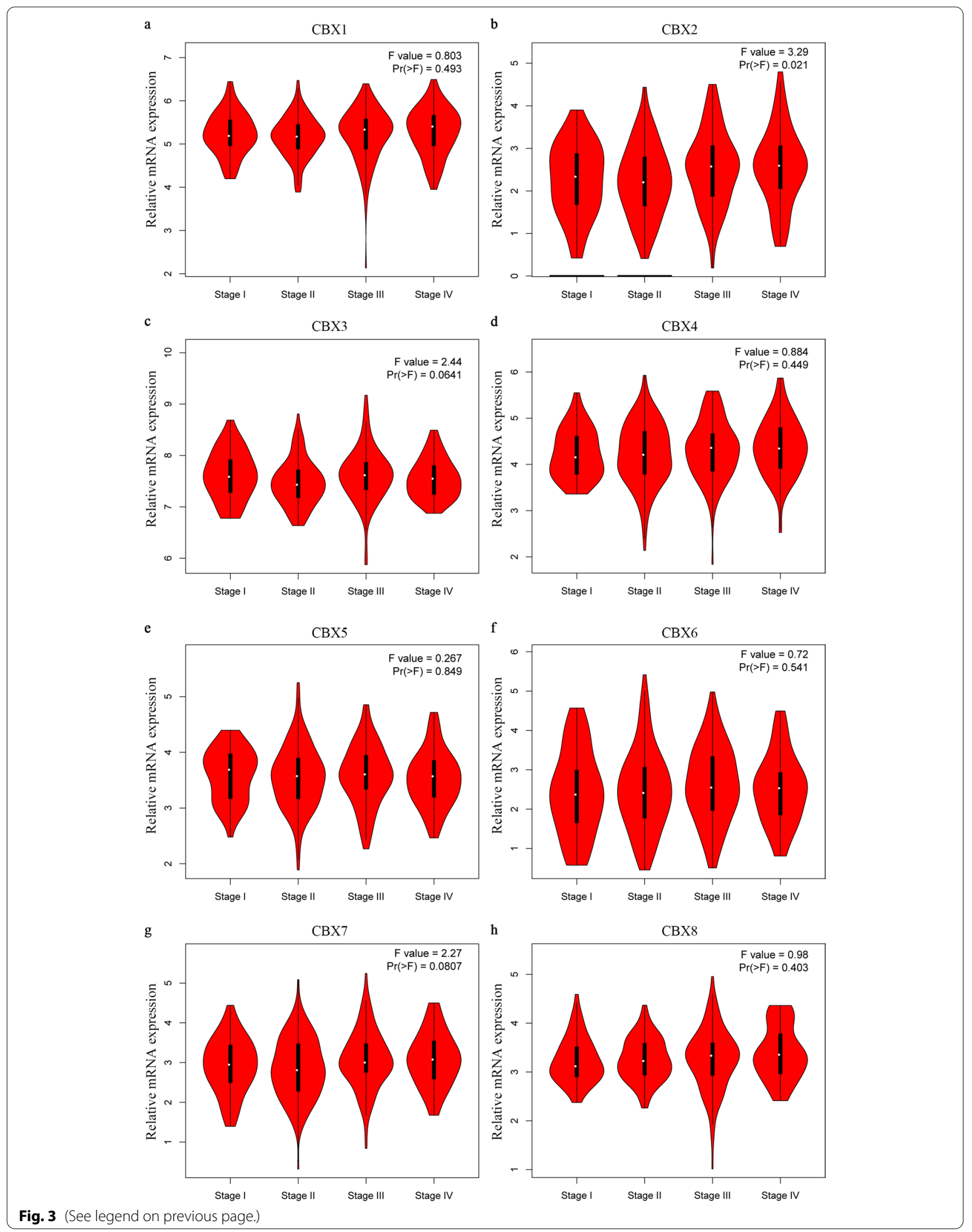




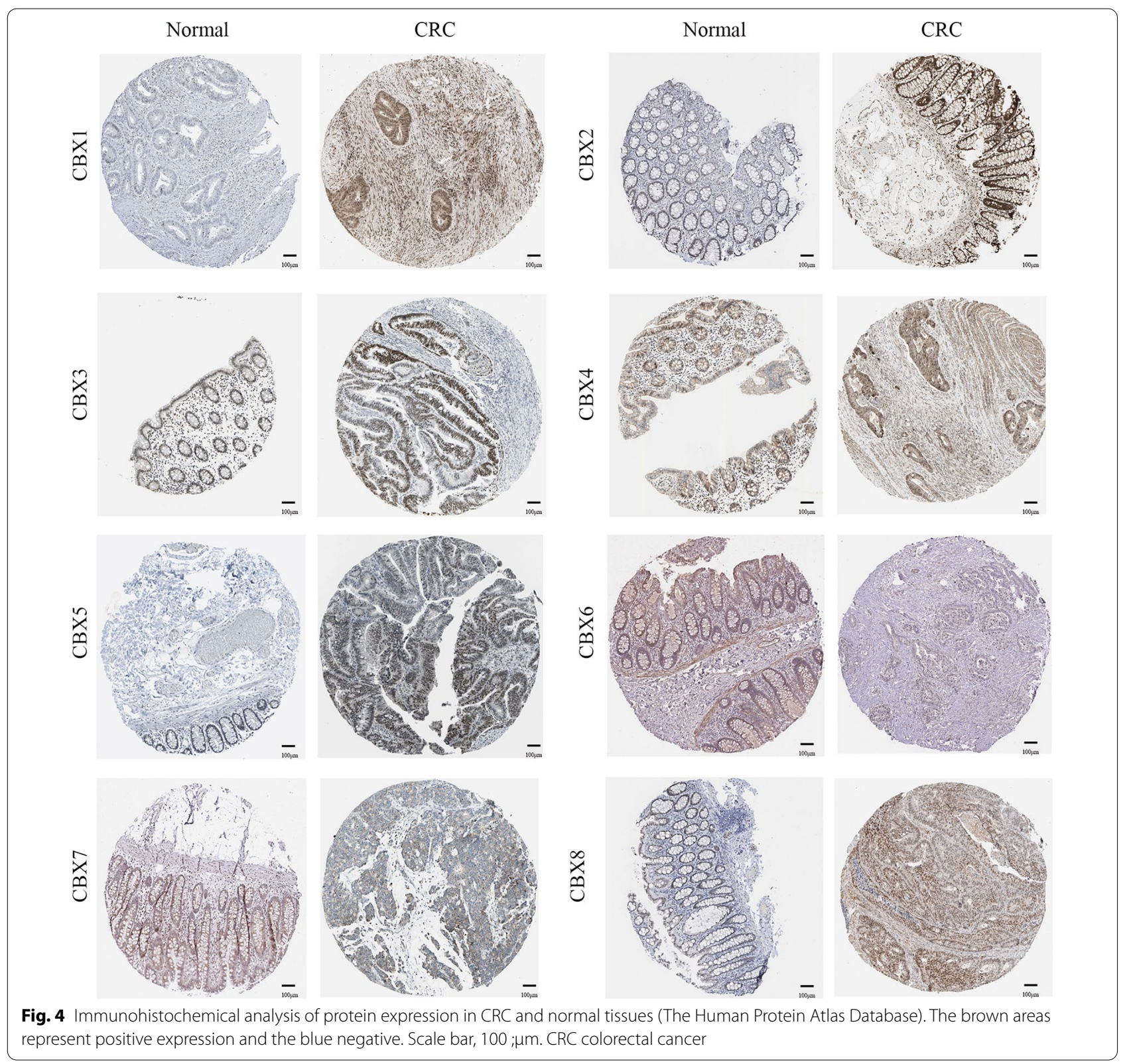

expression. These findings suggested that CBX2 may be a potential prognostic target. Further analysis of the CBX2 function found it to be highly expressed in CRC cell lines HCT116 and HT29, as compared to normal colon mucosal epithelial cell line. These results were consistent with the CCLE database. As mentioned above, CBX2 has been proven by numerous researchers to affect cell proliferation by binding to the Ink4a/ Arf locus [50]. Consistent with previous observations, the present in vitro experiments indicated that
CBX2-knockdown significantly inhibited cell proliferation and invasion in HCT116 and HT29 cell lines. In addition, Daub et al. performed a proteomics study to search for cellular targets in cancer cells, and found that CBX2 was involved in the cell cycle, whose dysregulation could induce apoptosis [51]. Through apoptosis assays, it was confirmed that the downregulation of CBX2 could markedly promote apoptosis in HCT116 and HT29 cell lines. 

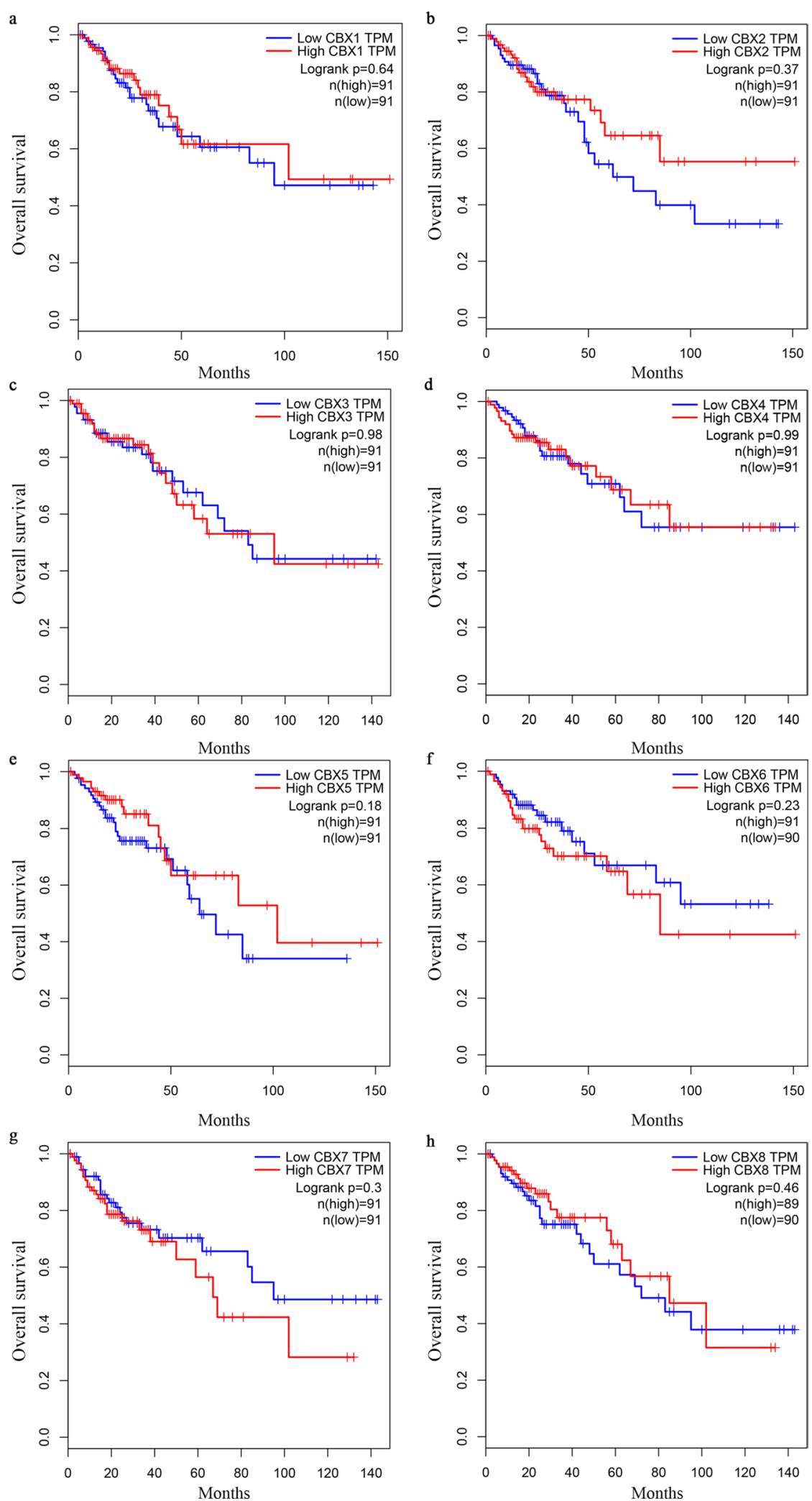

Fig. 5 Survival analysis and prognostic values of CBX family in patients with CRC (GEPIA database). a-h OS curves of CBX1, CBX2, CBX3, CBX4, CBX5, CBX6, CBX7, and CBX8 in patients with CRC. OS overall survival, HR hazard ratio, CRC colorectal cancer 

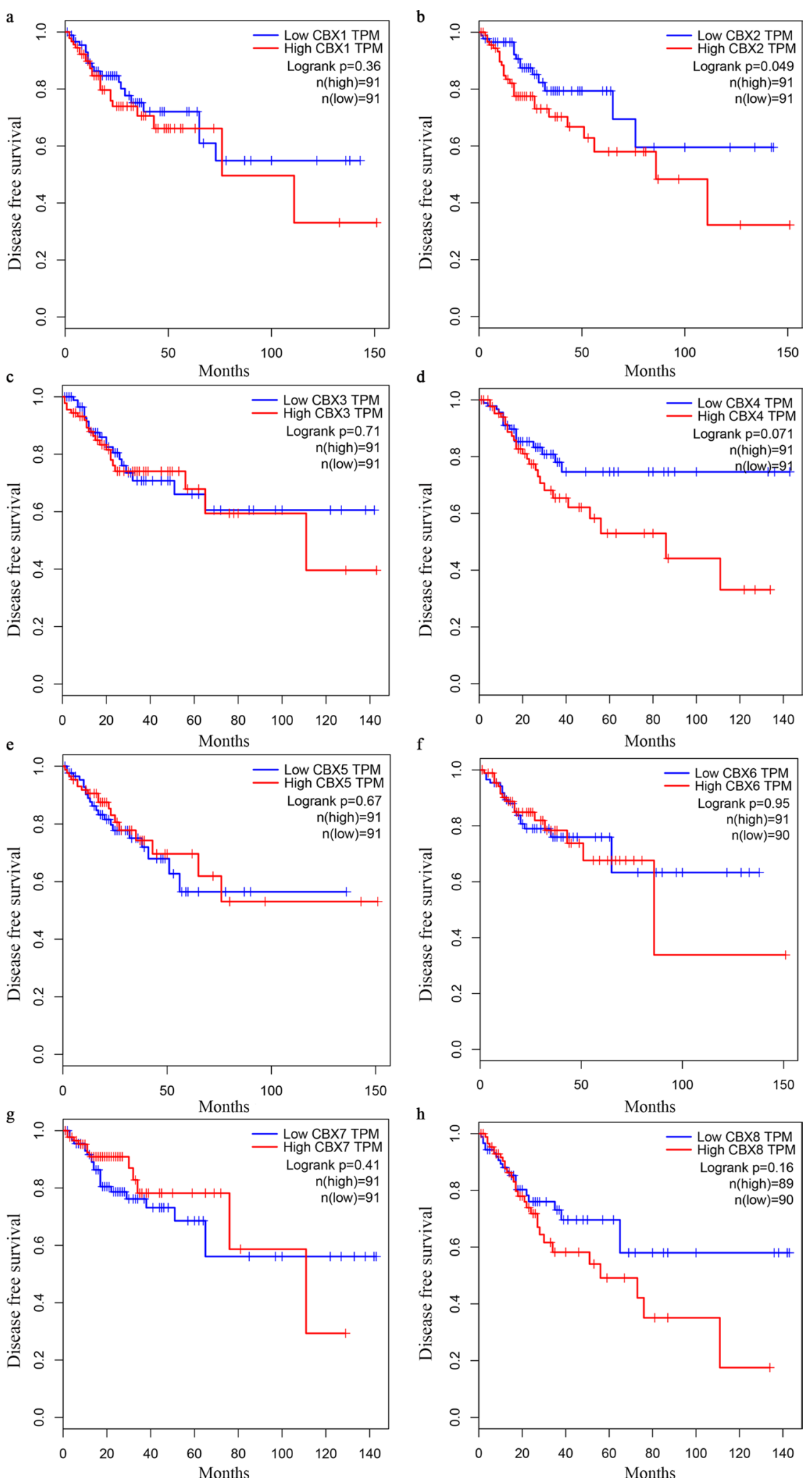

Fig.6 Survival analysis and prognostic values of CBX family in patients with CRC (GEPIA database). a-h DFS curves of CBX1, CBX2, CBX3, CBX4, CBX5, CBX6, CBX7, and CBX8 in patients with CRC. DFS disease-free survival, HR hazard ratio, CRC colorectal cancer 


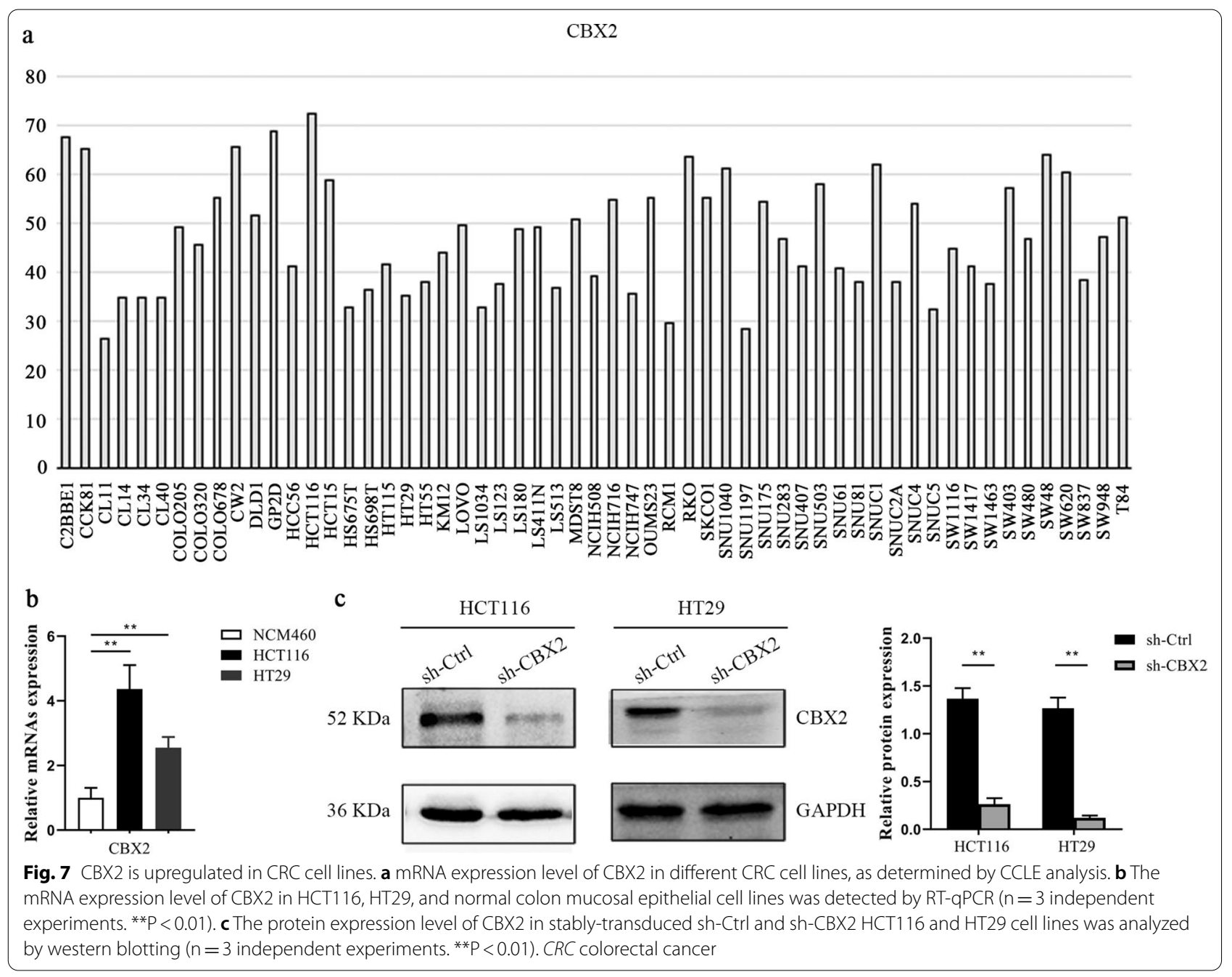

Inevitably, our research has some limitations. Firstly, we only studied the expression of the CBX family in CRC, while the mutation of the CBX family in CRC has not been further explored. Secondly, we have not further explored the mechanisms of epigenetics, such as signaling pathways. Thirdly, in the apoptosis assay, the cell viability value is relatively low (less than $85 \%$ ), but we will improve the experimental method in future research work. Even though the underlying molecular mechanism between the abnormal expression of CBX2 and $C R C$ requires more in-depth research, this study clearly confirmed that CBX2 is upregulated in CRC and CBX2-overexpression is significantly associated with poor survival outcomes. In conclusion, the present study suggested that CBX2 could function as an oncogene and serve as a potential prognostic biomarker in CRC.

\footnotetext{
(See figure on next page.)

Fig. 8 CBX2-knockdown inhibits CRC cell proliferation and invasion. a CBX2-knockdown suppressed cell proliferation, as determined by colony formation assays in HCT116 and HT29 cell lines ( $n=3$ independent experiments ${ }^{*} \mathrm{P}<0.01$ ). Scale bar, 100 magnification. $\mathbf{b}$ Apoptosis ratios of CBX2 in stably-transduced sh-Ctrl and sh-CBX2 HCT116 and HT29 cell lines were detected by flow cytometric analysis ( $\mathrm{n}=3$ independent experiments ${ }^{*} \mathrm{P}<0.025$, ${ }^{*} \mathrm{P}<0.01$ ). c Knockdown of CBX2 significantly inhibited cell invasion in HCT116 and HT29 cell lines ( $\mathrm{n}=3$ independent experiments, ** $P<0.01$ )
} 


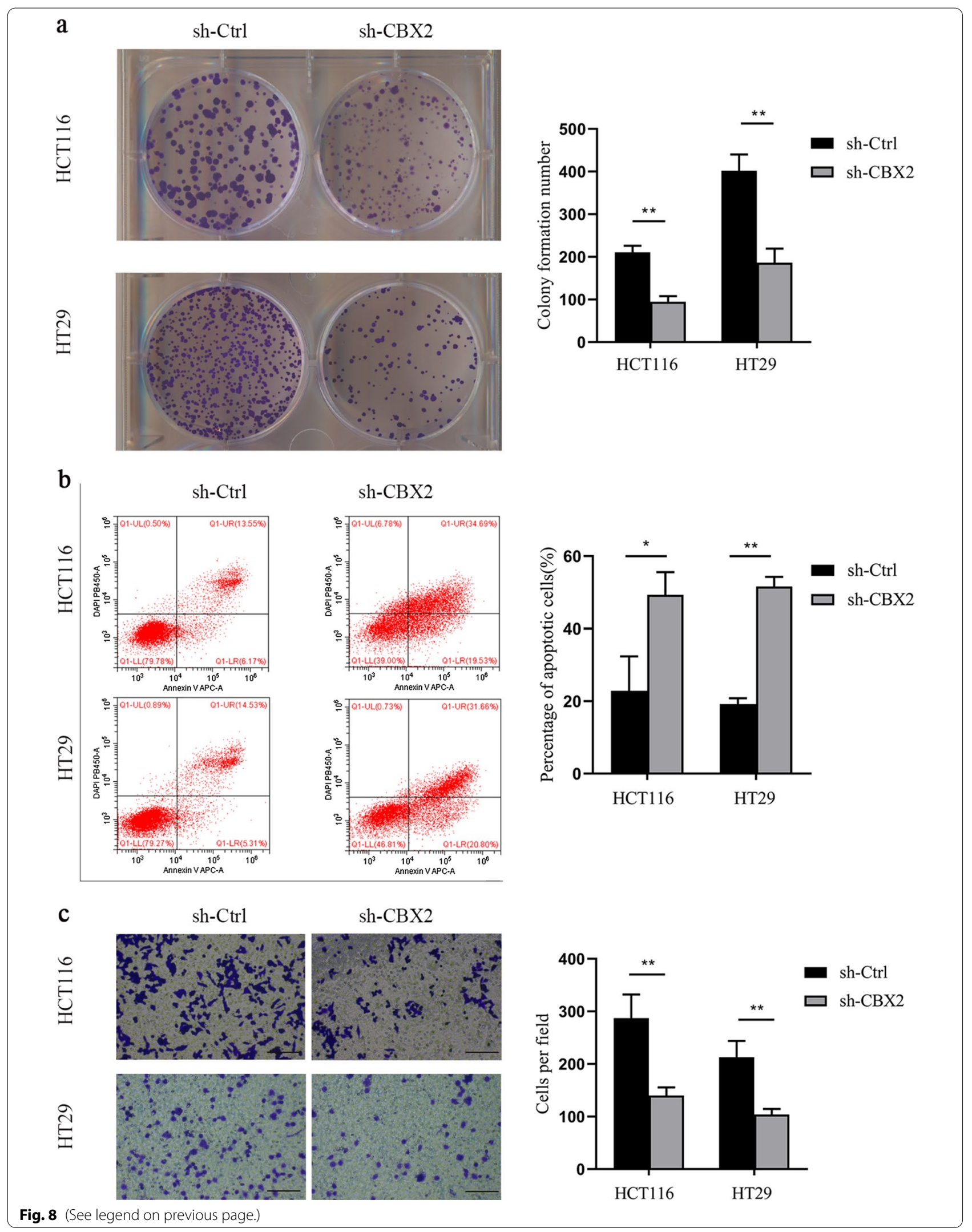




\section{Abbreviations}

CBX: Chromobox; RT-qPCR: Real time quantitative polymerase chain reaction CCLE: Cancer cell line encyclopedia; HPA: Human protein atlas database; GEPIA: Gene expression profiling interactive analysis; TCGA: The Cancer Genome Atlas; YAP: Yes-associated protein; RAS: Rat sarcoma virus.

\section{Authors' contributions}

$\mathrm{HZ}$ and TZ designed study; ZLL researched literature; $H Z$ and YFX performed experiments; SLH analyzed experimental results; $\mathrm{HZ}$ wrote the manuscript. All authors read and approved the final manuscript.

\section{Funding}

This work was supported by Youth Science Foundation Project, National Natural Science Foundation of China (82003147); Scientific Research Project of Affiliated Hospital of North Sichuan Medical College (2020ZD001, 2021ZD001); The Doctoral Research Startup Fund Project of North Sichuan Medical College (CBY20-QD03); Pre-research of State-level Project of North Sichuan Medical College (CBY19-YZ17); Free Exploring Basic Research Project of Science and Technology of Sichuan Province (2020YJ0186, 2021YJ0456); Nanchong Science and Technology Bureau National Natural Science Foundation Project Cultivation Special (20SXZRKX0004); Scientific and Technological Cooperation Project of Nanchong City (19SXHZ0290, 18SXHZ0511).

\section{Availability of data and materials}

The datasets generated and analyzed during the current study are publicly available from the following online databases: CCLE (https://portals.broad institute.org/ccle/home); Oncomine database (http://www.oncomine.org); HPA database (https://www.proteinatlas.org/); GEPIA database (http://gepia. cancer-pku.cn/)

\section{Declarations}

\section{Ethics approval and consent to participate}

Not applicable.

\section{Consent for publication}

Not applicable.

\section{Competing interests}

The authors declare that they have no competing interests in this work.

\section{Author details}

${ }^{1}$ The Second Department of Gastrointestinal Surgery, Affiliated Hospital of North Sichuan Medical College, 63 Wenhua Road, Nanchong 637000, Sichuan Province, China. ${ }^{2}$ The First Department of Hepatobiliary Surgery, Affiliated Hospital of North Sichuan Medical College, Nanchong 637000, Sichuan, China. ${ }^{3}$ Institute of Hepatobiliary, Pancreatic and Intestinal Disease, North Sichuan Medical College, Nanchong 637000, Sichuan, China.

Received: 21 March 2021 Accepted: 21 July 2021

Published online: 28 July 2021

\section{References}

1. Torre LA, Bray F, Siegel RL, Ferlay J, Lortet-Tieulent J, Jemal A. Global cancer statistics, 2012. CA Cancer J Clin. 2015:65(2):87-108.

2. Siegel RL, Miller KD, Jemal A. Cancer statistics, 2019. CA Cancer J Clin. 2019;69(1):7-34

3. Arnold M, Sierra MS, Laversanne M, Soerjomataram I, Jemal A, Bray F. Global patterns and trends in colorectal cancer incidence and mortality. Gut. 2017:66(4):683-91.

4. Sigurdsson JA, Getz L, Sjönell G, Vainiomäki P, Brodersen J. Marginal public health gain of screening for colorectal cancer: modelling study, based on WHO and national databases in the Nordic countries. J Eval Clin Pract. 2013:19(2):400-7.

5. Compton CC. Optimal pathologic staging: defining stage II disease. Clin Cancer Res. 2007:13(2):6862s-70s.

6. Cuyle PJ, Prenen H. Current and future biomarkers in the treatment of colorectal cancer. Acta Clin Belg. 2017:72(2):103-15.
7. Gonzalez-Pons M, Cruz-Correa M. Colorectal cancer biomarkers: where are we now? BioMed Res Int. 2015;2015:149014.

8. Li G, Reinberg D. Chromatin higher-order structures and gene regulation. Curr Opin Gent Dev. 2011;21(2):175-86

9. Zhou VW, Goren A, Bernstein BE. Charting histone modifications and the functional organization of mammalian genomes. Nat Rev Genet. 2011:12(1):7-18

10. Ma RG, Zhang Y, Sun TT, Cheng B. Epigenetic regulation by polycomb group complexes: focus on roles of CBX proteins. J Zhejiang Univ SC B. 2014;15(5):412-28

11. Wotton D, Merrill JC. PC2 and SUMOylation. Biochem Soc Trans. 2007:35(6):1401-04

12. Vincenz C, Kerppola TK. Different polycomb group CBX family proteins associate with distinct regions of chromatin using nonhomologous protein sequences. PNAS. 2008;105(43):16572-77.

13. Aloia L, Di Stefano B, Di Croce L. Polycomb complexes in stem cells and embryonic development. Development. 2013;140(12):2525-34

14. Gieni RS, Hendzel MJ. Polycomb group protein gene silencing, noncoding RNA, stem cells, and cancer. Biochem Cell Biol. 2009;87(5):711-46.

15. Carone DM, Lawrence JB. Heterochromatin instability in cancer: from the Barr body to satellites and the nuclear periphery. Semin Cancer Biol. 2013;23(2):99-108

16. Mao J, Tian Y, Wang C, Jiang K, Li R, Yao Y, et al. CBX2 regulates proliferation and apoptosis via the phosphorylation of YAP in hepatocellular carcinoma. J Cancer. 2019:10(12):2706-19.

17. Zheng H, Jiang WH, Tian T, Tan HS, Chen Y, Qiao GL, et al. CBX6 overexpression contributes to tumor progression and is predictive of a poor prognosis in hepatocellular carcinoma. Oncotarget. 2017;8(12):18872-84.

18. Xia ZB, Anderson M, Diaz MO, Zeleznik-Le NJ. MLL repression domain interacts with histone deacetylases, the polycomb group proteins HPC2 and BMI-1, and the corepressor C-terminal-binding protein. PNAS. 2003:100(14):8342-7.

19. Simhadri C, Gignac MC, Anderson CJ, Milosevich N, Dheri A, Prashar N et al. Structure-activity relationships of Cbx7 inhibitors, including selectivity studies against other cbx proteins. ACS Omega. 2016;1(4):541-51.

20. van den Boom V, Rozenveld-Geugien M, Bonardi F, Malanga D, van Gosliga D, Heijink AM, et al. Nonredundant and locus-specific gene repression functions of PRC1 paralog family members in human hematopoietic stem/progenitor cells. Blood. 2013;121(13):2452-61.

21. Morey L, Pascual G, Cozzuto L, Roma G, Wutz A, Benitah SA, et al. Nonoverlapping functions of the polycomb group $\mathrm{Cbx}$ family of proteins in embryonic stem cells. Cell Stem Cell. 2012;10(1):47-62.

22. Pontén F, Jirström $K$, Uhlen M. The human protein atlas a tool for pathology. J Pathol. 2008;216(4):387-93.

23. Markert EK, Levine AJ, Vazquez A. Proliferation and tissue remodeling in cancer: the hallmarks revisited. Cell Death Dis. 2012;3(10):e397.

24. Hanahan D, Weinberg RA. The hallmarks of cancer. Cell. 2000;100(1):57-70.

25. Stratton MR, Campbell PJ, Futreal PA. The cancer genome. Nature 2009;458(7239):719-24

26. Ni Z, Wang $X$, Zhang T, Li L, Li J. Comprehensive analysis of differential expression profiles reveals potential biomarkers associated with the cell cycle and regulated by p53 in human small cell lung cancer. Exp Ther Med. 2018;15(4):3273-82

27. Li J, Li WX, Bai C, Song Y. Particulate matter-induced epigenetic changes and lung cancer. Clin Respir J. 2017;11(5):539-46.

28. Byler S, Goldgar S, Heerboth S, Leary M, Housman G, Moulton K, et al. Genetic and epigenetic aspects of breast cancer progression and therapy. Anticancer Res. 2014;34(3):1071-7.

29. Babaei K, Khaksar R, Zeinali T, Hemmati H, Bandegi A, Samidoust $P$, et al. Epigenetic profiling of MUTYH, KLF6, WNT1 and KLF4 genes in carcinogenesis and tumorigenesis of colorectal cancer. Biomedicine. 2019;9(4):22.

30. Yokomichi N, Nishida N, Umeda Y, Taniguchi F, Yasui K, Toshima T, et al. Heterogeneity of epigenetic and epithelial mesenchymal transition marks in hepatocellular carcinoma with keratin 19 proficiency. Liver Cancer. 2019;8(4):239-54.

31. Piunti A, Shilatifard A. Epigenetic balance of gene expression by polycomb and COMPASS families. Science. 2016:352(6290):aad9780. 
32. Lao W, Grady WM. Epigenetics and colorectal cancer. Nat Rev Gastro Hepat. 2011;8(12):686-700.

33. Fearon ER, Vogelstein B. A genetic model for colorectal tumorigenesis. Cell. 1990;61(5):759-67.

34. Okugawa Y, Grady WM, Goel A. Epigenetic alterations in colorectal cancer: emerging biomarkers. Gastroenterology. 2015;149(5):1204-25.

35. Rhee YY, Kim MJ, Bae JM, Koh JM, Cho NY, Juhnn YS, et al. Clinical outcomes of patients with microsatellite-unstable colorectal carcinomas depend on L1 methylation level. Ann Surg Oncol. 2012;19(11):3441-8.

36. Rijnsoever MV, Elsaleh H, Joseph D, McCaul K, lacopetta B. CpG island methylator phenotype is an independent predictor of survival benefit from 5-fluorouracil in stage III colorectal cancer. Clin Cancer Res. 2003;9(8):2898-903.

37. Lee S, Cho NY, Choi M, Yoo EJ, Kim JH, Kang GH. Clinicopathological features of CpG island methylator phenotype-positive colorectal cancer and its adverse prognosis in relation to KRAS/BRAF mutation. Pathol Int. 2008;58(2):104-13.

38. Barchitta M, Maugeri A, Li Destri G, Basile G, Agodi A. Epigenetic biomarkers in colorectal cancer patients receiving adjuvant or neoadjuvant therapy: a systematic review of epidemiological studies. Int J Mol Sci. 2019;20(15):3842.

39. Morey L, Helin K. Polycomb group protein-mediated repression of transcription. Trends Biochem SCI. 2010;35(6):323-32.

40. Obuse C, Yang H, Nozaki N, Goto S, Okazaki T, Yoda K. Proteomics analysis of the centromere complex from HeLa interphase cells: UV-damaged DNA binding protein 1 (DDB-1) is a component of the CEN-complex, while BMI-1 is transiently co-localized with the centromeric region in interphase. Genes Cells. 2004;9(2):105-20.

41. Parfett CL, Desaulniers D. A Tox21 approach to altered epigenetic landscapes: assessing epigenetic toxicity pathways leading to altered gene expression and oncogenic transformation in vitro. Int J Mol SCl. 2017;18(6):1179.

42. Herceg Z, Lambert MP, van Veldhoven K, Demetriou C, Vineis P, Smith MT, et al. Towards incorporating epigenetic mechanisms into carcinogen identification and evaluation. Carcinogenesis. 2013;34(9):1955-67.
43. Chen WY, Zhang XY, Liu T, Liu Y, Zhao YS, Pang D. Chromobox homolog 2 protein: a novel biomarker for predicting prognosis and taxol sensitivity in patients with breast cancer. Oncol Lett. 2017;13(3):1149-56.

44. Clermont PL, Crea F, Chiang YT, Lin D, Zhang A, Wang JZ, et al. Identification of the epigenetic reader CBX2 as a potential drug target in advanced prostate cancer. Clin Epigenet. 2016;8:16.

45. Di Costanzo A, Del Gaudio N, Conte L, Dell'Aversana C, Vermeulen M, de Thé $H$, et al. The HDAC inhibitor SAHA regulates CBX2 stability via a SUMO-triggered ubiquitin-mediated pathway in leukemia. Oncogene. 2018;37(19):2559-72.

46. Han Q, Li C, Cao Y, Bao J, Li K, Song R, et al. CBX2 is a functional target of miRNA let-7a and acts as a tumor promoter in osteosarcoma. Cancer Med. 2019;8(8):3981-91.

47. Ning G, Huang $Y L$, Zhen $L M, X u W X$, Jiao $Q$, et al. Transcriptional expressions of chromobox $1 / 2 / 3 / 6 / 8$ as independent indicators for survivals in hepatocellular carcinoma patients. Aging. 2018;10(11):3450-73.

48. Liang YK, Lin HY, Chen CF, Zeng D. Prognostic values of distinct CBX family members in breast cancer. Oncotarget. 2017;8(54):92375-87.

49. Jiang N, Niu G, Pan YH, Pan WW, Zhang MF, Zhang CZ, et al. CBX4 transcriptionally suppresses KLF6 via interaction with HDAC1 to exert oncogenic activities in clear cell renal cell carcinoma. EBioMedicine. 2020;53:102692.

50. Jangal M, Lebeau $B$, Witcher $M$. Beyond $E Z H 2$ : is the polycomb protein CBX2 an emerging target for anti-cancer therapy? Expert Opin Ther Targets. 2019;23(7):565-78.

51. Daub H, Olsen JV, Bairlein M, Gnad F, Oppermann FS, Körner R, et al. Kinase-selective enrichment enables quantitative phosphoproteomics of the kinome across the cell cycle. Mol Cell. 2008;31(3):438-48.

\section{Publisher's Note}

Springer Nature remains neutral with regard to jurisdictional claims in published maps and institutional affiliations.
Ready to submit your research? Choose BMC and benefit from:

- fast, convenient online submission

- thorough peer review by experienced researchers in your field

- rapid publication on acceptance

- support for research data, including large and complex data types

- gold Open Access which fosters wider collaboration and increased citations

- maximum visibility for your research: over 100M website views per year

At BMC, research is always in progress.

Learn more biomedcentral.com/submissions 